\title{
Realismo social y censura en la novela española (1954-1962)
}

\section{FERNANDO LARRAZ \\ Universidad de Alcalá}

\author{
Cristina SuÁrez Toledano \\ Universidad de Alcalá
}

Título: Realismo social y censura en la novela española (1954-1962).

Resumen: Este trabajo tiene como objetivo poner de manifiesto la relación entre los postulados y la práctica de la novela del Realismo social en Espańa entre 1954 y 1962 y el contexto de censura editorial durante la dictadura franquista. Se analizarán algunas de las explicaciones teóricas sobre el Realismo social emanadas por los autores a la luz de las necesidades expresivas para sortear la censura. También serán explicadas las respuestas de los censores ante algunas de las novelas más representativas de esta década como factores que determinaron la hegemonía del Realismo y su posterior decadencia en el campo literario.

Palabras clave: Realismo social, Censura, Novela, Objetivismo.

Fecha de recepción: 17/12/2017.

Fecha de aceptación: 23/12/2017.
Title: Social Realism and Censorship in the Spanish novel (1954-1962).

Abstract: This paper aims to expose the relationship between the tenets and the practice of the social realist novel in Spain between 1954 and 1962 and the context of book censorship during Francoist dictatorship. Some theoretical explanations on social Realism by the authors themselves will be analysed under the perspective of their needs to overcome censorship. Censors' responses to some of the most representative novels of this decade will be explained too as factors which determined the hegemony of Realism in the literary field and its later decadence.

Key words: Social Realism, Censorship, Novel, Objetivism.

Date of Receipt: 17/12/2017.

Date of Approval: 23/12/2017.

\section{INTRODUCCIÓN}

Con este trabajo aspiramos a establecer una relación causal entre la estética realista dominante en la producción narrativa del medio siglo en 
España y su relación con el sistema censorio al que estaban sometidos los escritores. Esta relación fue puesta de manifiesto por algunos de ellos en su momento (de manera acusadamente explícita por Juan Goytisolo en sus artículos "Escribir en España” y "Los escritores españoles ante el toro de la censura", incluidos después en El furgón de cola) pero no ha sido hasta ahora estudiada de forma sistemática ${ }^{1}$. Nuestra hipótesis es que la censura condicionó las propuestas literarias de los escritores espańoles durante el franquismo, al tener que dar con soluciones retóricas que permitieran representar culturalmente la realidad social y las ideologías desde las que se interpretaba; ideologías que no necesariamente coincidían con la que intentaba imponer el Régimen a través de los mecanismos de control cultural. En este sentido, la narrativa dominante durante la década de 1950 supuso una reacción de los autores con el fin de tratar de compaginar su necesidad de comunicación con el público español y las restricciones a las que los sometían los censores. Obviamente, la censura editorial no explica por sí misma el Realismo social o cualesquiera otros movimientos artísticos o culturales que se sucedieron durante los años que duró el Régimen franquista, pero sí supone una de las influencias más determinantes y cabe, por tanto, pensar que la historia de la literatura espańola, a través de sus sucesivos paradigmas, habría sido distinta de no haberse visto los artistas obligados a sortear los criterios restrictivos de los censores.

En resumen, se trata de proponer una interpretación del paradigma del Realismo social hegemónico en los años cincuenta no como una mera elección estética, sino también como una solución a la coacción comunicativa impuesta por el contexto. Esto no aparece explícitamente en los textos teóricos de los novelistas. Por ello, se cotejarán estas propuestas con la doctrina oficial del franquismo, tal como consta en los informes de censura, a fin de formular hipótesis acerca del grado, las causas y la forma de apoyo o rechazo del sistema de represión cultural al Movimiento.

1 Un esbozo de esta problemática está incluido en Fernando Larraz, Letricidio español. Censura y novela durante el franquismo, Gijón, Trea, 2014, pp. 203-278. 


\section{ORÍGENES DEL REALISMO SOCIAL}

El origen de lo que podría llamarse el dogma del Realismo social puede rastrearse en ciertas revistas de principios de los cincuenta que heredan el radical antivanguardismo de la doctrina estética falangista. Estos jóvenes universitarios habían velado sus primeras armas literarias bajo la inspiración de consignas emanadas de su obligatoria militancia seuísta, bajo cuyo paraguas, en revistas como Alférez, Alcalá, Juventud o La Hora, era posible disentir de la deriva económica y social del Régimen, o mejor, advertir frente a los desvíos de la doctrina falangista que supuestamente le informaba.

Los miembros de esta primera generación universitaria del franquismo, nacidos entre 1922 y $1927^{2}$, y por tanto sin apenas experiencia directa de la cultura republicana, derivaron hacia posiciones políticas muy diversas. Muchos acabarían copando los puestos más elevados de la jerarquía política del tardofranquismo. Los que se dedicaron a la poesía y a la narrativa formarían la llamada "Generación del Medio Siglo", caracterizada, en sus inicios, por una fuerte adhesión a los principios del Realismo social. En ellos prevaleció el aprendizaje de sus años mozos: la coherencia generacional, su conciencia de vocación y destino un tanto mesiánicos, su aversión ante el uso gratuito de la inteligencia... Refiriéndose a los novelistas, Francisco Álamo Felices añade a su caracterización "su común formación en una ignorancia literaria tremenda, el origen, casi idéntico, de clase de estos intelectuales, con un marcado inconsciente ideológico pequeño-burgués y la compartida experiencia de una niñez marcada por la guerra"3.

A partir de los años cincuenta del siglo XX, unos cuantos de los miembros de esta generación comienzan a hacerse visibles en el campo cultural español y, tomando como guías a otros intelectuales algo mayores, consolidan la corriente literaria que se ha denominado Realismo social. Parten de la apropiación de una técnica estrictamente objetivista tomada de diversas fuentes y se dedican a describir distintas situaciones que po-

2 Juan Triguero [seudónimo de José María Moreno Galván], "La generación de Fraga y su destino", Cuadernos del Ruedo Ibérico, 1 (1965), pp. 5-16.

3 Francisco Álamo Felices, La novela social española. Conformación ideológica. Teoria y crítica, Almería, Universidad, 1996, p. 112. 
nen de relieve las injusticias sociales del momento, especialmente el sufrimiento del proletariado y del campesinado, la ociosidad de los burgueses y la banalidad y amoralidad que caracterizaban sus vidas y, en general, la alienación de todos los miembros de la sociedad respecto de unas normas no conocidas ni controladas conscientemente. Todo ello conllevaba una sucesión literaria de existencias malogradas, sin horizontes vitales más allá de la repetición monótona de unos hábitos que debían generar en el lector compasión, solidaridad y conciencia de participar de un sistema caduco.

Mediante tal retrato, la literatura cumplía una función de denuncia respecto de la anomalía de la situación presente y de alerta de la necesidad de una regeneración de un cuerpo social enfermo, de manera análoga a la misión emprendida por los realistas del siglo anterior. Resultan ilustrativas las siguientes palabras de Santos Sanz Villanueva:

Bastantes escritores del medio siglo compartieron la idea de que la literatura tenía un valor instrumental y debía desarrollar una función política. La situación histórica del hombre fue preocupación asumida por una mayoría, pero mientras unos defendían el relato de agitación y propaganda, otros se detuvieron en una narrativa objetivista y testimonial que se quedaba en la frontera de la soledad y frustración de las personas. Estos últimos practican, pues, un testimonio de solidaridad con el sufrimiento y una actitud humanitaria ${ }^{4}$.

Los escritores (narradores, poetas, dramaturgos y cineastas) afines a esta corriente pueden ordenarse, como ha señalado Ramón Buckley ${ }^{5}$, en dos grupos bien diferenciados: el grupo madrileño y el grupo barcelonés, adscritos a sendas revistas, Revista Española y Laye, respectivamente. Este paradigma realista se configuró como la corriente de escritura más conveniente para unos autores que pretendían hacer llegar a los lectores una denuncia contra los patrones socialmente establecidos en la España reciente, caracterizada por el desarrollo de un sistema capitalista de mercado, sin que pudiera haber, por causa de la dictadura, discursos teóricos que cues-

4 Santos Sanz Villanueva, La novela española durante el franquismo, Madrid, Gredos, 2010, p. 179.

5 Ramón Buckley, La doble transición. Política y literatura en la España de los años setenta, Madrid, Siglo XXI. 
tionaran su conveniencia ni plantearan sistemas económicos y sociales alternativos, excepción hecha de aquellos que, salvaguardados por la vieja doctrina falangista de la revolución socialsindicalista, seguían reivindicando límites para el desarrollo del capitalismo y de clases oligárquicas de la sociedad española.

Por ello, quizá no sea del todo equivocado situar al menos parcialmente los orígenes del Realismo social del medio siglo en Espańa y de su retórica objetivista en el periodo de crisis que comenzó a gestarse hacia 1950 , cuando se acrecentó entre los jóvenes intelectuales falangistas de la primera generación universitaria de la posguerra la sensación de que se estaban quedando sin un "lugar bajo el sol" de la Victoria. Su desengaño ante el carácter reaccionario, rancio, corrupto y burgués de la sociedad de posguerra los llevó a posiciones críticas visibles de manera muy explícita en sus órganos de expresión, que, eso sí, salvaban siempre a la jefatura del Estado y se apoyaban en José Antonio como fuente de verdad indiscutida. Abundaron, en efecto, las muestras de frustración, las llamadas a la "revolución pendiente" y las críticas a los nuevos patrones sociales que se habían impuesto sobre la imagen patriótica y desinteresada del falangista dibujada en su día por el fundador de Falange.

La datación de este cambio coincide con el nombramiento, en 1951, de Joaquín Ruiz-Giménez al frente del Ministerio de Educación Nacional, que es considerado como el inicio de una nueva etapa aperturista que se alargó hasta su cese en 1956. En este contexto, la irrupción de los narradores de la llamada Generación literaria del Medio Siglo supuso un hondo revulsivo para las letras españolas. Ideológicamente, sus fuentes partían de un falangismo de izquierdas, cada vez más confuso y desengañado, nutrido de un espíritu rebelde y crítico que paulatinamente se fue cargando de ideología al hacerse palpable la existencia de agudos conflictos de clase que ni el franquismo tenía intención de superar ni ninguna revolución nacional sindicalista iba a ser capaz de afrontar ${ }^{6}$. La máxima falangista de la unidad del destino de España quedaba desmentida por la realidad, y la conciencia de este hecho los llevó, en algunos casos de manera progresiva y, en otros, de manera radical, a trocar la revolución falangista por la revolución socialista $y$, de paso, a ensayar uno de los

6 Barry Jordan, Writing and Politics in Franco's Spain, Londres y Nueva York, Routledge, 1990, p. 36. 
acercamientos más ortodoxos a las propuestas sartrianas de la literatura comprometida.

El credo de la literatura social o socialista concordaba parcialmente con las consignas literarias falangistas de la década anterior, que repudiaban una literatura encerrada en sí misma, sin más función que la reflexión sobre su lenguaje y con un valor extrarreferencial totalmente irrelevante. Antes bien, se apostó por una nítida manifestación de las inestabilidades del sistema social, una crítica de las trivialidades de la vida burguesa española y una descripción de las ordenaciones de poder que permitían las injusticias sociales. Para ello, hacía uso de un lenguaje altamente denotativo y de una exposición casi naturalista de las relaciones sociales y del sistema de ideas que las sustentaba. Acento Cultural, Alcalá, La Hora y Revista Española recogieron en sus páginas algunas de aquellas inquietudes —más sociales que políticas - en su primera fase e impusieron el paradigma, un Realismo social inquietante y objetivista basado en la utopía de la utilidad del arte como medio de transformación. Se trataba de estimular así una conciencia de los desequilibrios sociales y políticos que condujera a la acción colectiva. Algunos de estos autores se dedicaron a esbozar un acercamiento a las "masas obreras" que con frecuencia tenía mucho de populismo romántico. Hacia este punto parecían dirigirse las tempranas palabras de José María Castellet cuando reconoció que "el anticonformismo ha perdido la partida en nuestra generación"7.

Por otra parte, su ineludible vinculación a las publicaciones del SEU otorgó a estas proclamas una orientación nueva y paradójica, en la que la tan pregonada unidad espiritual de los españoles venía a converger con una renovada manifestación de las diferencias de intereses de clase. Constituían, al mismo tiempo, la primera generación de jóvenes formados en aulas expurgadas de resabios liberales y republicanos, y, por tanto, las primeras evidencias de las limitaciones en la formalización del pensamiento crítico que sobre la creación literaria demostró tener el franquismo. Si durante la década de 1940 la excepcionalidad de la narrativa española se debía a la expatriación de sus más apreciables valores, a ello se sumaban ahora las insuficiencias de unos autores cuyo talento estaba desperdiciado por la desorientación y la falta de referentes. Entre los abundantes testi-

7 José María Castellet, Notas sobre literatura española contemporánea, Barcelona, Laye, 1955, p. 12. 
monios de estas rémoras de su formación, recogemos a modo de ejemplo este de Juan Goytisolo:

\begin{abstract}
Desde la perspectiva de hoy, lo sucedido entonces conmigo y otros escritores espańoles me parece inevitable. Nuestra orfandad intelectual y el yermo cultural en el que vivíamos nos alentaban a incurrir en los errores y deslices de quienes, privados de todo asidero, se esfuerzan en dar los primeros pasos. Aterrados del vacío que súbitamente descubríamos alrededor de nosotros, abrazábamos un cuerpo doctrinal nítido y coherente que nos permitía forjar deprisa una teoría explicativa de nuestro retraso: importada pieza por pieza de Francia o de Alemania, la defensa primero del "Behaviorismo" y luego del "Realismo crítico" serían el tributo que pagaríamos a la miseria intelectual de la posguerra en nuestro afán bien intencionado de eliminarla. Como dice T. S. Eliot, en una cita espigada en un reciente y luminoso libro de José Ángel Valente, "para teorizar hace falta una inmensa ingenuidad; para no teorizar hace falta una inmensa honestidad". Fatalmente incluidos en el bando de los ingenuos, nuestra tarea de derribar las puertas abiertas se envolvía de cara a España en unos criterios elementales de pragmatismo ${ }^{8}$.
\end{abstract}

El artículo de Goytisolo "Para una novela nacional popular" (1957) ${ }^{9}$ evidencia precisamente ese desconocimiento que los escritores espańoles del interior tenían no solo de las corrientes europeas de vanguardia de su tiempo, sino también de la corriente social de preguerra. Goytisolo, representando aquí a los del interior, poseía una sesgada visión de la narrativa espańola anterior a 1936, dominada en exclusiva por un lenguaje vacío, heredero de las premisas estéticas del arte deshumanizado de Ortega. La ignorancia sobre los escritores sociales españoles, las tesis del Nuevo Romanticismo, las editoriales de avanzada y aun el sentido social de las vanguardias en Espańa eran abrumadoras y reflejan bien a las claras cómo la ausencia de lecturas o la vaga memoria de lecturas incompletas e indirectas tanto de la tradición española como de la literatura europea contemporánea fue determinante en la génesis del movimiento.

8 Juan Goytisolo, Coto vedado, Barcelona, Seix Barral, 1985, pp. 196-197.

9 Juan Goytisolo, "Para una Literatura Nacional Popular”, Insula, 146 (1959), pp. 6 y 11 . 


\section{El REALISMO SOCIAL COMO DOCTRINA LITERARIA}

Durante bastante tiempo, los órganos culturales del Régimen permitieron la fama de la novela realista y anularon su potencial subversivo, apropiándose de su mensaje crítico. Tomando como ejemplo un artículo de 1961 del crítico y sacerdote Ignacio Elizalde, vemos cómo esta tendencia se encuadra en "un imperativo moral de sinceridad inconformista, que puede ser tan honrado o más que el tranquilo conformismo que se empeña en proclamar la realidad positiva de la nación". Ante la imposibilidad de crear un gusto estético acorde con sus mitos, y en plenos esfuerzos de integración internacional, convenía potenciar la marca del Realismo social como una muestra de normalidad, como una tendencia literaria que emparejaba a los novelistas españoles con "la novela social contemporánea en Estados Unidos y Francia” y que contaba con su comprensión, pues aunque "cualquiera podría creer que en una nación, donde existe censura literaria, se evitarían aquellos temas de aire polémico, social o religioso", tal tendencia era incluso predominante, dentro de unos límites, en la vida literaria en España ${ }^{10}$. En contraste con el exilio, la oposición del interior podía ser encauzada y definida como un comprensible y aun patriótico inconformismo juvenil. Tales afirmaciones se insertan en el contexto del surgimiento de movimientos católicos de apostolado social muy a principios de la década de 1950, impulsados por el Servicio Universitario del Trabajo gracias a la popularidad del padre José María de Llanos. Y también por el éxito de cierta novela católica de inspiración social, aceptada por la jerarquía religiosa con el fin de acrecentar su aceptación entre las capas proletarias, escritores muy populares entonces, como José Luis Martín Descalzo y, después, José Luis Martín Vigil.

Por su parte, la práctica del Realismo social sirvió de coartada a los escritores para legitimar su labor frente al estigma de la censura, creando un discurso épico de la narrativa espańola desde 1939. Lo que se presentaba como admirable ya no era que en las severas condiciones del exilio se sostuviera la capacidad creadora, sino que esto ocurriera en la soledad vigilada de la España del interior, a la que se le otorgó un mérito mayor por

10 Ignacio Elizalde, "La novela social contemporánea en España”, Fomento Social, 63 (1961), pp. 255-269. 
las condiciones de oquedad cultural que los obligaba a escribir a tientas. "Si comparamos las circunstancias en que salen a la luz los autores de la promoción de 1927 con las que rodearon a nuestra generación de posguerra hacia el medio siglo, los contrastes son estremecedores" ${ }^{11}$, puesto que para los narradores de la primera posguerra "eran tiempos de heroísmo callado, de aguante sobrehumano, de sacrificio colectivo"12. El nuevo propósito consistía en excusar la labor novelística española. La perspectiva que ofrecían los acontecimientos históricos (revueltas estudiantiles de 1956) y literarios (triunfo del realismo social) obligaba a introducir modificaciones en el discurso. Comenzaron a ser encomiados el espíritu rebelde de la novela de la época y su carácter político, pero no politizado: "la novela española está profundamente comprometida con la vida y la historia actual del país"13, con la historia actual pero no con la pretérita. Junto a esta justificación ideológica, los cultivadores del Realismo social, en diferentes obras y artículos — publicados en revistas culturales—, trataron de dotar al movimiento de unas bases estéticas y de situarlo en una tradición literaria con vinculaciones nacionales e internacionales. Así pues, desde mediados de los cincuenta se produjo una intensa reflexión sobre qué era el Realismo literario y cuál era su importancia en el ámbito social y cultural. En un texto especialmente paradigmático, $L a$ hora del lector ${ }^{14}$, José María Castellet estableció una comparación entre el novelista decimonónico y el del siglo XX, destacando cómo la voz de los autores, enunciada a través de la retórica literaria y de la disposición novedosa de elementos discursivos, principalmente de la implicación de la subjetividad del narrador en la interpretación de la historia, había ido desapareciendo de las obras y cómo los narradores, y con ellos también los autores, van perdiendo entidad hasta convertirse en meros transcriptores de lo observado, eliminando consigo cualquier tipo de análisis o juicio de valor. Castellet contrapuso, pues, el modelo de novelar del siglo anterior a

11 José Corrales Egea, “¿Crisis de la nueva literatura? Reflexiones sobre una apuesta”, Insula, 223 (1965), pp. 3 y 10.

12 José Luis Castillo Puche, "La novela", en Panorama español contemporáneo. XXV años de paz, Madrid, Instituto de Cultura Hispánica, 1964, pp. 235-254.

13 José María Castellet, "La joven novela española", Sur, 284 (1963), pp. 48-54.

14 José María Castellet, La hora del lector. Notas para una iniciación a la literatura narrativa de nuestros dias, Barcelona, Seix Barral, 1957. 
las técnicas de creación literaria abanderadas por el Realismo social de los años cincuenta. Asimismo, puso de manifiesto la influencia del cine sobre la narrativa española de la época, afirmando que esta, al igual que lo haría una cámara, dejaba de lado cualquier atisbo de subjetividad al centrarse en la reproducción exacta de las conductas humanas. Si bien es cierto que Castellet describió en qué consistía la estética realista dominante en la novelística española del interior, también lo es que en su ensayo no se preguntó, de forma explícita, el porqué de su surgimiento.

Jesús López Pacheco, autor de una de las novelas más representativas del Realismo social —Central eléctrica (1958)_, también reflexionó sobre el nuevo modo de narrar que se había erigido como imprescindible en las producciones literarias de la época. En el artículo titulado "Realismo sin realidad"15, publicado en el primer número de Acento Cultural, establecía una distinción entre aquellos creadores y libros que empleaban un falso Realismo y aquellos otros que hacían uso de lo que él consideraba Realismo auténtico. Exigía una separación entre quienes entendían el Realismo como una mera técnica narrativa - una elección estética- y quienes, acertadamente, según el autor, comprendían la necesidad de reflejar la situación nacional, siendo consecuentes con ella y mostrándose fieles a una serie de principios como la rebeldía, la protesta, el dolor por el sufrimiento de las clases bajas y el deseo de justicia social. López Pacheco ponía de relieve la recurrencia con la que esta tendencia reaparecía en la literatura, de manera general, en situaciones históricas como la de España a mediados del siglo XX: "marcadas por signos de dolor, de injusticia, de desengaño respecto a ideales anteriores" 16 .

También en Acento Cultural, el dramaturgo Alfonso Sastre escribió acerca de estas cuestiones en su conocido manifiesto "Arte como construcción" 17 . En cuanto a la función que el arte tenía que desempeñar, Sastre evidenciaba la urgente necesidad de ocuparse de las injusticias, junto con el compromiso y la responsabilidad de los artistas con respecto a la sociedad, independientemente de su afiliación, o no, a un partido político. Al principio del artículo se remite a la utilidad de esta corriente en la época en la que comienza a desarrollarse. Desechando una vez más como

15 Jesús López Pacheco, "Realismo sin realidad", Acento Cultural, 1 (1958), pp. 5-7.

16 Ibidem.

17 Alfonso Sastre, “Arte como construcción”, Acento Cultural, 2 (1958), pp. 63-66. 
antimodelo los principios derivados de las tesis esteticistas y deshumanizadoras orteguianas, el autor reivindica la superioridad de la categoría social frente a la artística y hace referencia a los esfuerzos comunes en pos de la consecución del progreso y la transformación de un mundo injusto en uno que no lo sea. Sastre describe el "Social-Realismo" como un "arte de urgencia”, dada su capacidad para intervenir en el cuerpo social. De este modo, el dramaturgo apunta que la modalidad realista es, a su vez, social e integradora, por lo que atiende a temas como la libertad, la culpa o el arrepentimiento. Los artistas adscritos a este movimiento - "novelístico, dramático, poético, plástico y cinematográfico" — se sienten responsables y están comprometidos con el mundo en el que viven, frente a la posición adoptada por sus predecesores — seguidores de los diferentes ismos-, por lo que intentan reformar el panorama a través de sus obras, trabajando, además, en la construcción de un porvenir benéfico para todos.

De la lectura de este artículo-manifiesto puede colegirse que los escritores, aunque sometidos a la censura impuesta por el Régimen franquista, habían encontrado, gracias al Realismo social, un nuevo método para llegar a los lectores y hacerles partícipes de la oposición al sistema dictatorial. El surgimiento de este paradigma literario no se basaba en la simple aplicación de unas nuevas técnicas narrativas, sino que iba más allá y se relacionaba directamente con la obligación ética de los escritores para, sorteando la falta de libertad impuesta por la administración, transmitir sus ideas al público.

En lo que respecta a Juan Goytisolo, reflexionó profusamente sobre la tarea de escribir en España durante el franquismo y, específicamente, sobre la moda del Realismo social, a la que permaneció directamente ligado. En el volumen titulado El furgón de cola $(1967)^{18}$ se recogen varios artículos — publicados en prensa entre 1960 y 1966 — con claras alusiones a la problemática que supuso la producción de obras literarias en el país bajo la estricta mirada del sistema censorio. En "Los escritores españoles frente al toro de la censura", Goytisolo explica las razones por las que nuestra literatura se configuró, en la década de los cincuenta y sesenta, como una de las más comprometidas de Europa, siendo estas, principalmente, la inconformidad con el dogma político, religioso y moral establecido por

18 Juan Goytisolo, Obras completas. VI, Barcelona, Galaxia Gutenberg-Círculo de Lectores, 2009. 
el Régimen y la necesidad de testimoniar la realidad del momento - función que, en cierta medida, le habría correspondido más a la prensa que a la literatura- . No obstante, el novelista no puede evitar reconocerle a la censura el mérito "de haber estimulado la búsqueda de las técnicas necesarias al escritor para burlarla e introducir de contrabando [...] la ideología o temática 'prohibidas'"19, es decir, el desarrollo del Realismo social. A este respecto, cuestiona el éxito que habría tenido el Objetivismo de no haber existido la censura previa. Finalmente, Goytisolo acentúa la dimensión política y el carácter subversivo de estas obras que, lejos de ajustarse a las pautas y a la ortodoxia de lo que debía ser la literatura nacional espańola, surgió como un modo de eludir la censura impuesta por un Estado que trataba de intervenir en todos los ámbitos sociales y culturales del país.

En el artículo titulado "La literatura perseguida por la política", Goytisolo incide sobre lo desacertado que resulta, en ese contexto, comparar la situación que viven los narradores españoles con la de los franceses. Mientras que en el país vecino la libertad de expresión era un hecho en los años cincuenta y sesenta, en España los artistas se vieron forzados a luchar de forma encubierta por la libertad y los derechos de un pueblo oprimido. El autor valora, pues, el esfuerzo realizado en las novelas adscritas al paradigma realista, que actuaba como un espejo donde reflejar las injusticias padecidas por las clases sociales más desfavorecidas. Goytisolo deja entrever la necesidad de que la literatura española actúe como una solución a la coacción comunicativa impuesta por el Estado. Dado que los medios oficiales impedían la libertad, tanto política como de prensa, el novelista denuncia que las producciones literarias se vieran obligadas a politizarse para tratar de combatir contra la persecución. Así, la estética realista se configuró, según apunta Goytisolo, como un instrumento de oposición, símbolo de una ideología social que combatía de manera silenciosa, frente a la dictadura que atenazaba al país.

Igualmente, tanto en "Literatura y eutanasia" como en "Examen de conciencia", Goytisolo se refiere al alto grado de compromiso que asumieron los jóvenes escritores espańoles, entre los que se incluye. Los nombres cuyas obras pueden catalogarse como social-realistas, no conformes

19 Ibidem, pp. 60-61. 
con los órdenes preestablecidos — político, social, religioso, moral, artístico...- y notablemente influidos por los postulados marxistas, se decantaron por una corriente literaria que, a través de un lenguaje subversivo, los ayudaba a posicionarse en contra del régimen político. En ambos ensayos Goytisolo alude a la responsabilidad que, de forma implícita y ante las desigualdades sociales, adoptaron estos escritores. Sin embargo, el autor revela cómo ese compromiso les "condenaba a la rutina del Realismo fotográfico" ${ }^{20}$, por lo que el objetivismo con el que combatían la doctrina franquista también limitaba sus elecciones estéticas.

Estas y otras reflexiones hechas por parte de los cultivadores del Realismo social sobre qué era y a qué se debía su origen llevan a la conclusión de que este fue concebido como la manera de manifestar su inconformismo con respecto al control ejercido por el Estado sobre la sociedad española. Novelistas como Goytisolo señalaron en sus ensayos que esta nueva modalidad realista — que inundó todos los géneros literarios - contribuía a realizar el retrato, de forma certera, de una sociedad que había que transformar y liberar de la fiscalización oficial en todos los ámbitos de la vida cultural del país. El desacuerdo con el sistema franquista por parte de los intelectuales los movilizó a escribir obras inevitablemente politizadas en un momento en que la discusión política estaba fuertemente coaccionada en la esfera pública. Por lo tanto, quienes participaron en la creación literaria del momento justificaron su elección del Realismo social por entenderlo como una herramienta de oposición capaz de enfrentarse al Régimen al representar la presión, las injusticias y la falta de libertad en que vivía la sociedad.

\section{LA CENSURA Y EL REALISMO SOCIAL COMO PRAXIS NARRATIVA (I954-I956)}

La crítica ha asumido la distinción entre dos etapas de la narrativa del Realismo social o Realismo objetivo. Un primer ciclo de la década, protagonizado por Carmen Martín Gaite, Jesús Fernández Santos, Ignacio Aldecoa, Rafael Sánchez Ferlosio, Ana María Matute y Juan Goytisolo, apenas halló problemas con la censura hasta muy entrados los cincuenta,

20 Ibidem, p. 83. 
si exceptuamos dos o tres casos. Su realismo, con una inclinación más humanista que política, fue entendido, más que por su crítica implícita, por encuadrarse dentro del género "novela de costumbres", como califican los censores Solís y José María Hernández a Los bravos ${ }^{21}$, de Fernández Santos, y El fulgor y la sangre ${ }^{22}$, de Aldecoa, en enero y octubre de 1954 respectivamente.

Sí perciben los censores de estas novelas dos rasgos novedosos: uno, la estricta depuración del lenguaje altisonante, dogmático y retoricista de la escritura oficial franquista, de la que estos jóvenes escritores parecían haberse librado a través de una expresión sencilla, natural y humilde; y dos, un coloquialismo que, en su afán de expresión veraz y realista, los llevaba a introducir palabras malsonantes. Respecto a este afán de pulcritud léxica, las tachaduras de estas obras tratan precisamente de poner coto a las palabras excesivamente gruesas. En algunos casos, se propone su eliminación por el censor, si bien logró librarse Entre visillos, de Carmen Martín Gaite ${ }^{23}$. Otros, pese a señalar los desmanes léxicos, se muestran particularmente benévolos, como el lector Javier Dieta, quien interpretó así El Jarama, de Sánchez Ferlosio:

La novela se detiene en la descripción — realísima - de esas diez horas que los excursionistas pasan a orillas del río. El aburrimiento se rompe con la tragedia. Una de las chicas se ahoga. No hay más. Algo así como si se hubiese tomado en cinta magnetofónica aquellas conversaciones, todos los gritos, canciones, toda clase de ruidos etc. etc. Ahí debe estar el valor de la novela. Abundan los tacos que no considero suprimibles, aunque me parecen de muy mal gusto ${ }^{24}$.

No anda del todo desencaminada la exégesis del censor, pues aquel "no hay nada más” y el símil magnetofónico eran parte de la intención del autor. La liberalidad de no suprimir aquello que era considerado de mal gusto permitió que no se viera afectado el naturalismo expresivo de los personajes. El mismo criterio volvió a aplicar Dieta en el informe de Gran

21 Expte. 54-182: Los bravos, Jesús Fernández Santos. Archivo General de la Administración (AGA) 03 (50) 21/10598.

22 Expte. 54-6147: El fulgor y la sangre, Ignacio Aldecoa. AGA 03 (50) 21/10871.

23 Expte. 58-183: Entre visillos, Carmen Martín Gaite. AGA 03 (50) 21/11901.

24 Expte. 56-252: El Jarama, Rafael Sánchez Ferlosio. AGA 03 (50) 21/11319. 
Sol ${ }^{25}$, de Aldecoa, en agosto de 1956: "Se ponen en boca de sus personajes expresiones propias del medio ambiente, abundando las fuertes y aun las groseras, que consideramos no es preciso tachar". Sin embargo, otras novelas no corrieron igual suerte. A Con el viento solano, de Aldecoa, se le tacharon numerosas palabras mucho más leves que los tres "puta" que contenía El Jarama, lo cual es indicativo de la arbitrariedad del proceso.

La imposibilidad de mirar la realidad desde posiciones ideológicas explícitas convirtió estas obras en recreaciones puras, aparentemente neutras de la realidad más próxima de los autores. A esta pretendida inocencia se une que este periodo coincide con cierto beneplácito oficial, amparado desde el ministerio de Ruiz Giménez. De ahí que, más que flexibilización de la censura, lo que predomina es cierta asimilación por el sistema de estos fines, en pleno periodo de dominio del modelo comprensivo sobre el intransigente ${ }^{26}$. La excepción más llamativa en este periodo correspondió probablemente a la novela Luciérnagas ${ }^{27}$, de Ana María Matute, denegada en fecha tan temprana como noviembre de 1953 y que la catalana reescribió -y desfiguró- dos años después bajo el título de En esta tierra ${ }^{28}$.

\section{UN NUEVO MOLDE DE REALISMO SOCIAL (I957-I962)}

A partir de 1956, coincidiendo con el cese de Ruiz-Giménez al frente del Ministerio de Educación Nacional, el cerco censorio al paradigma literario del Realismo social se estrechó con mayor crudeza. En la segunda fase de este movimiento (1957-1962), los nuevos narradores que se incorporan al campo literario viraron hacia posiciones más radicales, en lo que se ha llamado "Realismo crítico", que no es sino una forma hispánica y rudimentaria de ensayo del Realismo socialista practicada bajo un régimen dictatorial: se produjo un aumento de la carga crítica en las

25 Expte. 56-3806: Gran Sol, Ignacio Aldecoa. AGA 03 (50) 21/11505.

26 Santos Juliá, "La 'falange liberal', o de cómo la memoria inventa el pasado", en $A u$ tobiografía en España: un balance, Celia Fernández y M. Ángeles Hermosilla (eds.), Madrid, Visor, 2004, pp. 127-144.

27 Expte. 53-6147: Luciérnagas, Ana María Matute. AGA 03 (50) 21/10494.

28 Marie-Lise Gazarian-Gautier, Ana María Matute. La voz del silencio, Madrid, Espasa-Calpe,1997, p. 91. 
narraciones, se denunciaron con mayor fuerza las precarias condiciones de trabajo del campesinado y el proletariado, se pusieron de manifiesto los excesos de la burguesía y se escenificó una realidad social de lucha de clases. Ya no se trata tanto de despertar la comprensión y caridad hacia las víctimas del sistema social, sino de la indignación y la reivindicación de justicia contra los culpables del mismo, que dejan de ser una fuerza anónima e inidentificable.

A partir de este momento, la mayoría de estas novelas sufrieron tachaduras relacionadas con palabras malsonantes o con pasajes referidos a la sexualidad y la política. Los censores criticaban especialmente aspectos de la novela social como la filosofía hedonista de la que hacían gala algunos de sus jóvenes protagonistas. A pesar de ello, la Sección de Inspección de Libros terminó aprobando la publicación de las mismas, llegando incluso a alabar los argumentos — concretamente aquellos en los que se apreciaban características del costumbrismo o en los que se dejaba entrever un justo afán de justicia - y el estilo literario de algunas de ellas. Así, el Realismo social aún siguió siendo, durante un tiempo, una tendencia literaria integrada en el sistema franquista.

Notable ejemplo de ello podría ser Central eléctrica $(1958)^{29}$, finalista del Premio Nadal en 1957. Escrita por López Pacheco, narra el proceso de construcción de una central eléctrica y, por consiguiente, de una presa cuyas aguas anegarán las casas y las tierras de Aldeaseca, cuya situación en la geografía española es desconocida. A pesar de que a los aldeanos se les promete la llegada del progreso y la creación de múltiples puestos de trabajo, las desigualdades sociales se hacen aún más notables hasta desembocar en unas terribles consecuencias: los accidentes laborales se sucederán y varios trabajadores encontrarán la muerte durante la construcción de la central. A lo largo del relato se ofrece a los lectores una "épica sovietizante del trabajo y el precio humano que ha de pagar el hombre ante y por el avance técnico" ${ }^{30}$. Al respecto de esta novela, en parte autobiográfica -el padre de López Pacheco fue montador de centrales hidroeléctricas-, el censor Dieta señaló que en su fondo latía "una hiriente crítica social". No obstante, tras desmenuzar su argumento, Dieta considera que, entre otras razones, la obra puede ser publicada — sin tachadura alguna-,

29 Expte. 57-1633: Central eléctrica, Jesús López Pacheco. AGA 03 (50) 21/11656.

30 Francisco Álamo Felices, op. cit., p. 102. 
dado que "al ser muy intelectual su exposición, no creo que tenga mucha difusión". Se observa aquí un ejemplo de cómo desde el sistema censorio se subestimaba tanto la capacidad de los lectores para entender las críticas subyacentes en las obras como la difusión de las mismas, a pesar de que la editorial Destino solicitara una tirada de 4.000 ejemplares.

Del mismo modo, la autorización de Las afueras $(1958)^{31}$, la ópera prima de Luis Goytisolo, procedió sin que la censura modificase o suprimiese oraciones o pasajes en su interior. Salvador Ortolá comienza el informe resumiendo el argumento de la novela:

Una novela sobre el campo, el pueblo catalán actual. Varias personas, varias familias labriegas catalanas. Su vida —un par de generaciones - desde antes del Movimiento hasta hoy. La ciudad, la industria, la mecanización del campo, son fantasmas que, como el tiempo, dejan su huella aun sobre aquellos que pretenden vivir alejados de ellos.

El paso de La piqueta (1959) ${ }^{32}$ por la censura resultó ser igual de afortunado que el de las dos novelas anteriores: fue autorizada sin sufrir tachaduras. La obra, de Antonio Ferres, fue inspeccionada por Octavio Díaz-Pinés, quien emitió un brevísimo informe en el que se limitaba a la descripción del argumento: la inminente demolición de una chabola en la que vive "una familia modestísima". El censor no supo, o no quiso, ver el simbolismo que se escondía detrás de una novela en la que los protagonistas habían resultado vencidos tras la Guerra Civil y decidió proceder a su autorización.

Lo mismo sucedió con La mina $(1960)^{33}$, finalista del Premio Nadal en 1959, escrita por Armando López Salinas, otro de los autores de esta tendencia literaria, militante del PCE. A diferencia de lo que ocurriría después con Por el río abajo (1962) —de autoría compartida con Alfonso Grosso y tildada por la censura como un libro en el que se observa "cierta solapada crítica del Régimen" ${ }^{4}$ _ , la novela fue autorizada sin tachadu-

31 Expte. 58-4305: Las afueras, Luis Goytisolo. AGA 03 (50) 21/12129.

32 Expte. 59-2974: La piqueta, Antonio Ferres. AGA 03 (50) 21/12449.

33 Expte. 60-654: La mina, Armando López Salinas. AGA 03 (50) 21/12666.

34 Expte. 62-827: Por el río abajo, Alfonso Grosso y Armando López Salinas. AGA 03 
ras. De hecho, el lector Ortolá alaba que se trate de una obra "sin demagogia, sin moraleja y con vigor y objetividad", antes de pasar a resumir su argumento: las vicisitudes que padece un campesino andaluz que se desplaza al norte de la península para trabajar en una mina en la que se encontrará cara a cara con la muerte. Sin embargo, la benevolencia con la que fue tratada desde la institución censoria se podría justificar tras el estudio realizado por David Becerra —en la edición que realizó de la obra, en $2013^{35}$ — en el que afirma que "fueron los mismos editores de Destino quienes, en un ejercicio de autocensura, decidieron enviar a los departamentos de la censura la novela previamente mutilada por ellos mismos" 36 . En esta renovada edición de La mina se presenta la versión original del texto, sin censurar, obtenida a partir de la edición francesa que vio la luz en 1962. Concuerda con la hipótesis ofrecida por Becerra la detallada investigación realizada por José Andrés de Blas ${ }^{37}$, quien asegura que la amabilidad del censor en el informe sobre la obra, su autorización sin tachaduras, se debió al esfuerzo de López Salinas por autocensurarse - tanto la concreción de referencias espacio-temporales como los pasajes de contenido con mayor violencia y alusiones políticas - y no a una supuesta bondad arbitraria por parte de Ortolá. Con respecto al final esperanzador, tras la serie de infortunios que sufre el protagonista y que dejan un panorama sumamente desolador, De Blas afirma que "le suprimen el final - cuya comunicación podía haberse hecho por una vía de la que no había quedado constancia documental - y el autor se ve obligado a añadir otro a modo de 'pasaporte moral'"38.

Las novelas de la segunda etapa del Realismo social no solo ponían de manifiesto las precarias situaciones laborales y las injusticias padecidas por el proletariado y el campesinado. La ociosidad de la juventud burguesa — sus vicios y excesos, las infidelidades, el llamado "dolcevitismo" o hedonismo exacerbado, la falta de compromiso social... - también que-

(50) 21/13781.

35 David Becerra, "Estudio preliminar", en A. López Salinas, La mina, Madrid, Akal, 2013, pp. 5-112.

36 Ibidem.

37 José Andrés de Blas, "La mina: vicisitudes de una investigación sobre la censura literaria en España”, Represura, 2 (2017), pp. 56-95.

38 Ibidem. 
daba representada en muchas de estas obras, verbigracia en Encerrados con un solo juguete $(1960)^{39}$, la primera novela de Juan Marsé. Andrés y Tina son los protagonistas de este texto: dos jóvenes que, provenientes de familias burguesas y desestructuradas a raíz de la Guerra Civil, centran su existencia en el devenir del tiempo y no presentan iniciativa alguna. Díaz-Pinés, el lector que evaluó la obra, no consideró necesaria la supresión o modificación de ningún pasaje, si bien es cierto que en su informe coincidió con la novela en su crítica a "el juego de existir anodino, falso, sin término", de los jóvenes protagonistas, a los que llega a a comparar con "juguetes tristes y somnolientos".

Un caso diferente es el de La zanja $(1961)^{40}$, escrita por Alfonso Grosso, que se sirve de la descripción del trabajo de unos obreros que cavan una zanja, en un pueblo desconocido de la geografía espańola, para realizar una inusitada crítica sobre la organización social del momento. En el informe correspondiente, Juan Fernández Herrón consideró que la novela podía ser autorizada si se realizaban supresiones en quince páginas. Por lo demás, el censor se limitó a resumir el contenido de la obra y a justificar que el lenguaje empleado era "crudo y malsonante" como resultado de una adecuada caracterización de los personajes. También Herrón fue el encargado de evaluar Diario de una maestra $(1961)^{41}$, escrita por Dolores Medio. La protagonista de la novela es Irene Gal, maestra al igual que la autora - cuya relación con la censura había sido bastante negativa desde la solicitud de edición, en 1952, de Nosotros, los Rivero-, que imparte sus clases en una pequeña localidad rural. Los acontecimientos se desarrollan desde mediados de los años treinta hasta, aproximadamente, 1950, por lo que la situación social descrita se enmarca antes, durante y después de la Guerra Civil, como bien señala en su informe el censor. Además de contextualizar la obra, Herrón critica las "técnicas educativas que pretenden tener sabor de modernidad", reflejadas en la novela, en alusión al institucionismo de la maestra protagonista, y añade que en ella destaca una "falta de proyección hacia lo alto y sentido e intención de trascendencia, precisamente en la vida y en la obra de una Maestra, espańola y cristiana, que debe conocer y servir al fin supremo de toda educación cristiana

39 Expte. 60-4014: Encerrados con un solo juguete, Juan Marsé. AGA 03 (50) 66/05255.

40 Expte. 61-935: La zanja, Alfonso Grosso. AGA 03 (50) 21/13171.

41 Expte. 60-5465: Diario de una maestra, Dolores Medio. AGA 03 (50) 21/12993. 
entendido". De esta manera, Herrón deja clara su postura con respecto al texto: no solo no aprueba la forma de ser de los personajes — tilda a la protagonista de "ingenua y desvergonzada" —, sino que, además, opina que la obra "está demasiado atenida a la dimensión humana, terrenal de las cosas". A pesar de todo ello, el censor considera que la novela se puede autorizar si se hacen efectivas tachaduras en más de veinte páginas. Años más tarde, igual que en casos anteriores, Medio estimó oportuna la interposición de una petición, dirigida a la Dirección General del Ministerio de Información y Turismo, en la que solicitaba la autorización íntegra de Diario de una maestra, alegando razones como que "nada tiene de ofensivo para la Religión ni para la Patria", "que todo lo suprimido en la mencionada novela está expresado con la delicadeza de una pluma femenina, de la manera más suave posible", "que lo suprimido son palabras, párrafos, soliloquios, que la autora supone de importancia vital para la mejor comprensión de la novela”... El recurso fue aceptado y la obra fue, finalmente, autorizada de forma íntegra por un censor, Francisco Aguirre, quien, a pesar de que caracterizaba a la protagonista como "inmoral en su vida privada”, pensaba que esta solo sería leída por "personas ya mayores”, por lo que no atentaba contra las mentes de aquellos jóvenes cuyas conciencias el Realismo social pretendía despertar.

Por último, cabe comentar el caso de Dos dias de setiembre $(1962)^{42}$, escrita por José Manuel Caballero Bonald y autorizada sin ninguna tachadura. En ella se reflejan fielmente la precariedad laboral, las dificultades en las que tienen que moverse gran parte de los jornaleros y el abuso de poder del que hacen gala los señoritos andaluces. A pesar de que en la novela se recrea "la muerte violenta de un vendimiador aplastado por una cuba llena de mosto", el censor, Enrique Conde, parece alabarla principalmente por su componente costumbrista. Así pues, como se ha podido comprobar, los autores pertenecientes a la segunda etapa del realismo social pretendían reflejar en sus novelas las desigualdades existentes entre las diferentes clases sociales de la época. La censura, no obstante, solía responder favorablemente a la autorización de la mayoría de las obras, siempre y cuando en estas se suprimiesen o modificasen las palabras malsonantes y los pasajes que atentasen contra la moral católica.

42 Expte. 62-1498: Dos días de setiembre, José Manuel Caballero Bonald. AGA 03 (50) 21/13840. 


\section{6. ÚLTIMOS COLETAZOS DEL REALISMO SOCIAL: LAS NOVELAS IMPOSIBLES}

Como ya se ha expuesto, numerosas novelas fueron autorizadas a condición de que se suprimieran los pasajes peor considerados por los censores. Sin embargo, ya en la década de los sesenta se percibe una acentuación del componente crítico, que señala directamente a los culpables (clases y grupos sociales, instituciones, prácticas religiosas y culturales) de la injusticia y el sometimiento del pueblo. Aquellos títulos, presentados ante la censura entre 1960 y 1962, se corresponden con el momento en el que los lectores oficiales —en especial aquellos que desempeñaban cargos eclesiásticos - comenzaron a considerar que la publicación de textos de un realismo tan pronunciado era injustificable, a pesar de que su aparente fin fuera realizar una crítica de los vicios de gran parte de la sociedad, así como de la falta de valores propios del nacional-catolicismo. Y fueron recurrentes dos argumentos que, hasta entonces, aunque en ocasiones esgrimidos, apenas había tenido fuerza: primero, que la crítica ejercida no ofrecía solución dentro del sistema político y religioso del nacionalcatolicismo; y, segundo, su absoluto materialismo, su falta de una solución moral y espiritual a los problemas descritos.

Algunos de los ejemplos más destacados del Realismo social considerados impublicables, presentados todos ellos por Seix Barral, son particularmente representativos ${ }^{43}$. Por ejemplo, en junio de 1960 la casa catalana solicitó la edición de La isla $(1961)^{44}$, de Juan Goytisolo. En la novela - que había sido concebida de forma inicial como un extenso y completo guion para una película que dirigiría Ricardo Muñoz Suay - se narra cómo Claudia Estrada, su protagonista, disfruta de las vacaciones de verano en la concurrida Torremolinos. Remontándose al pasado ya vivido, la voz narrativa en primera persona describe con precisión sus entradas y salidas, los encuentros con otros miembros de la clase acomodada, las relaciones personales que se establecen entre ellos... Relatos, en suma, que no agradaron al primer censor que se enfrentó a su lectura, Miguel de la Pinta. Tras realizar tachaduras en más de ciento cincuenta páginas, el lector esboza en pocas palabras cuál es el argumento y se detiene en ofrecer algunos juicios negativos. Señala, entre otras cosas, que en la obra

43 Véase Fernando Larraz, op. cit., pp. 244-261.

44 Expte. 60-3214: La isla, Juan Goytisolo. AGA 03 (50) 73/06844. 
se aprecia "tal cúmulo de obscenidades que resulta imposible su publicación”. Ante esta denegación, el editor Víctor Seix redactó una carta en la que ponía de manifiesto la repercusión que tendría para Espańa que el libro de Goytisolo se publicase traducido en otros países y que no llegara a ver la luz en territorio nacional. Sin embargo, estos alegatos no surtieron efecto, puesto que pasó a manos de un segundo lector, Saturnino Álvarez Turienzo —un censor religioso, altamente cualificado y experto en diferenciar cuáles eran las novelas cuyo contenido atacaba a la moral y, por tanto, no debían llegar a manos de los españoles-, que no solo suscribió las palabras de su colega con respecto a la falta de decoro de los personajes, sino que, además, señaló que en el texto se podían encontrar "insinuaciones malévolas sobre la Cruzada española, sobre la jerarquía eclesiástica y civil y sobre algunos de sus representantes". De nuevo, se rechazó su autorización. La obra fue publicada en México y no comenzó a venderse en las librerías españolas hasta principios de los años ochenta.

El paso de Los vencidos $(1965)^{45}$, de Antonio Ferres, por la administración censora tampoco resultó afortunado. En diciembre de 1960 se solicitó permiso para la edición de un texto en el que se reflejaban las duras condiciones de vida con las que tenían que lidiar quienes habían salido exiliados tras la Guerra Civil española. La opresión carcelaria, las represalias hacia los republicanos derrotados y el dolor al que se enfrentan sus viudas se abrían paso en un relato de gran crudeza que no dejaba muy bien parada la imagen del bando nacional, de los vencedores frente a los vencidos. Cuenta de ello da el primer censor en redactar un informe. En él, aduce cuatro motivos por los que le parece inviable que la novela se publique: la descripción del sistema penitenciario español, el favoritismo hacia el bando vencido, el dibujo de "una España, triste, hambrienta y oprimida” y el empleo de un léxico inadecuado. Como respuesta, Ferres escribió una carta dirigida al Servicio de Inspección de Libros en la que se mostraba confuso ante la denegación de la que sería la primera parte de una trilogía y se apresuraba a solicitar una revisión del expediente en cuestión. A pesar de que el autor trató de restarle importancia a los hechos planteados a causa del tiempo transcurrido —unos veinte años atrás-, el censor encargado de revisar el texto, Herrón, siguió oponién-

45 Expte. 60-6872: Los vencidos, Antonio Ferres. AGA 03 (50) 21/13101. 
dose a su autorización. Además de criticar la insistencia en asuntos como el hambre y la cantidad desbordante de presos en las cárceles, deja constancia de que

la objetividad debería dejar claramente expresado que aquello no responde, ni mucho menos, al ordinario sistema penitenciario espańol y que la cantidad de detenidos y presuntos delincuentes comunes desbordaba las posibilidades de una situación en que hubo de improvisarse tantas cosas, y esto es precisamente lo que no se hace, con lo que se presta al equívoco cuanto de buena intención pueda haber en el autor de "Los vencidos".

De esta manera, la autorización volvió a ser denegada. Traducida al italiano, la primera edición — que pasó a titularse I vinti-, en 1962, corrió a cargo de la editorial Feltrinelli. Tres años más tarde vio la luz en castellano, en Francia, dentro de la colección comunista Ebro y, hasta 2005, a cargo de la editorial Gadir, no fue reeditada en España. Poco tiempo después de la denegación de Los vencidos, Ferres vio cómo el maltrecho proceso se repetía con $A l$ regreso de Boiras ${ }^{46}$ — titulada de forma inicial Al regreso del Boila - En el informe del censor, firmado en marzo de 1962, se resume brevemente el argumento —el regreso de un exiliado a su pueblo natal, en la provincia de Burgos, y los incidentes que tienen lugar a su alrededor - y se califica como "completamente inadmisible, anti-régimen en grado superlativo e inmoral”, esto es, no publicable. Un segundo lector, como respuesta ante el recurso interpuesto por los interesados, deniega la solicitud de edición y suscribe que el libro "es abierto y claramente tendencioso desde el primero al último renglón” y que la imagen que ofrece de la actividad del bando nacional durante la Guerra Civil no es la correcta. Asimismo, el censor emite un inusitado juicio de valor sobre la editorial que avala la publicación, Seix Barral, al tildarla de "inequívocamente tendenciosa", al no ser esta la primera ocasión en la que pretende que vean la luz las obras más hirientes del Realismo social de la época, "como si con ello buscara ir minando los fundamentos de la actual realidad política de España”. Tuvieron que pasar cuatro décadas para que la obra se publicase —en 2002_ en España.

46 Expte. 62-1421: Al regreso del Boila, Antonio Ferres. AGA 03 (50) 21/13833. 
Para seguir con la estela de denegaciones, se debe analizar el caso de Tormenta de verano (1962) ${ }^{47}$, escrita por Juan García Hortelano, cuya publicación se prohibió en España en distintas ocasiones. El padre Álvarez Turienzo resumía así el argumento:

Crónica escandalosa de una colonia de verano en la Costa Brava. Toda la trama se desenvuelve a partir del caso de una joven que aparece muerta, desnuda, en la playa. La descubren unos niños en los que empieza ya a descubrirse una curiosidad malsana por lo sexual, e incluso en el caso de uno de ellos, como aparece más tarde, otros instintos realmente de precocidad alarmante.

A continuación, detallaba todos aquellos aspectos que impedían su autorización: "atentatorio contra el único sentido aceptable de la moral católica", "crónica de una sociedad corrompida", "si alguna moral subsiste en el relato es la de que el que no se aprovecha de lo que hay, de los que encuentra a mano, es un minusvalente"... Álvarez Turienzo hace notar que, como sucede con las demás novelas imposibles de la época, la censura no puede avalar la publicación de un texto en el que, si bien su intención inicial parece ser criticar los excesos, vicios y corrupciones de la sociedad, la representación realista llega a ser soez, de mal gusto, inadmisible, en definitiva, "tanta corrupción no se justifica por un difuso bien querer de sentido moral dudoso". A pesar de estas críticas, la novela recibió el Premio Formentor, por lo que aparecería íntegramente y de forma simultánea en diversos países del mundo. A este respecto, editores de ciudades como Turín, París, Nueva York, Londres o Ámsterdam escribieron a la Dirección General del Ministerio de Información y Turismo solicitando, de nuevo, la autorización en España. La cooperación de importantes agentes del panorama literario internacional contribuyó de manera notable, junto con los recursos impuestos por la editorial originaria — de nuevo Seix Barral-, a que Tormenta de verano viese la luz meses después, no sin antes ser denegada de nuevo y tras sufrir tachaduras y modificaciones en más de veinte páginas. De hecho, el encargado de elaborar un segundo informe de la novela fue otro religioso, Avelino Esteban y Romero, quien no solo

47 Expte. 61-3459: Tormenta de verano, Juan García Hortelano. AGA 03 (50) $21 / 13375$. 
suscribía las palabras de su colega, sino que, además, añadía comentarios en la misma línea: "se limita a presentar una serie de inmoralidades, sin que exista en su narración la contrapartida que compense sus atrevimientos descriptivos", "el posible alboroto que pueda suscitarse en torno a esta prohibición, servirá de compensación al escándalo internacional que dará una novela de este estilo, debida a un autor de un país confesionalmente católico", "pocas veces un libro está más justamente prohibido”...

Otro de los autores más comprometidos de la época, López Salinas, vio cómo Año tras año ${ }^{48}$ era rechazada por la censura española en junio de $1961^{49}$. En ella se ofrecía a los lectores un detallado retrato de la posguerra madrileńa y de la pervivencia de la lucha obrera frente a las desigualdades sociales y la opresión política. De naturaleza "claramente filocomunista", la novela fue considerada "terminantemente impublicable". A decantarse por este veredicto contribuyó notablemente, según el censor, la abundancia de párrafos soeces que calificaban el contenido total de la obra. En el recurso impuesto pocos días después por la editorial se argüía que la novela carecía de "afirmaciones de tipo político ni de ninguna otra clase que pudieran resultar censurables" puesto que la temática central se basaba "en el análisis de la problemática de orden moral, psicológico y de las relaciones humanas en el ámbito del proletariado español". A pesar de que se rogaba la concesión de la autorización, la censura reiteró su prohibición. Año tras año fue publicada desde 1962 en la editorial Ruedo Ibérico, en París.

También en junio de 1961 se presentó ante la Inspección de Libros Estos son tus hermanos ${ }^{50}$, de Daniel Sueiro, la historia de Antonio Medina, un exiliado que regresa a una España muy diferente a la que dejó y en la que no es bien recibido — ni siquiera por parte de su familia y sus antiguos vecinos-, hecho que le llevará a marcharse de nuevo. La publicación del texto se denegó y se emitieron hasta cinco informes al respecto. En el primero se critican la "tendencia general anti-Régimen", las referencias a la religión y a la Falange y la opinión que tienen los personajes de España. En el recurso presentado, Sueiro defiende que "la

48 Expte. 61-3458: Año tras año, Armando López Salinas, Madrid, 1961. AGA 03 (50) 21/13375.

49 David Becerra, "Se reedita Año tras año, la primera novela de Armando López Salinas", Mundo Obrero, 285 (2015).

50 Expte. 61-3752: Estos son tus hermanos, Daniel Sueiro. AGA 03 (50) 21/13403. 
nueva versión de dicha obra no atenta contra los principios básicos (tanto de índole religiosa y política como social) de nuestra vida nacional, ni resulta ofensiva para las ideas ni para las personas que rigen la actual convivencia española”. Atribuye a su imaginación, a la ficción creada por el escritor, todos los hechos representados y pretende así distanciarlos de la realidad para, después, suplicar la autorización. El censor Dieta insistió fervientemente en la denegación y se quejó de que "ahora va resultar que los buenos son los otros, los que están fuera; que los malos, los asesinos, hemos sido nosotros y esto lo dicen o lo insinúan hasta los que se tienen por nosotros". A continuación, Sueiro restaba importancia a la posible difusión del texto, pero como respuesta Álvarez Turienzo calificaba la novela de "bastante envenenadora, francamente impolítica, acusatoria". Posteriormente, Conde la autorizó con algunas modificaciones, aunque informaba de que "la tesis de la intransigencia está presente en toda la obra, salpicada de un realismo fraseológico bronco y excesivamente realista como es tónica de cierta literatura actual”, haciendo así referencia a todas las novelas del Realismo social. El último informe, firmado por Herrón, supone un exhaustivo análisis sobre Estos son tus hermanos en el que, finalmente, se recomienda la modificación de más de treinta páginas. El regreso a España de un exiliado no agrada a unos censores que se alzan como fervientes defensores de la hipótesis de que la lectura del texto no solo es perniciosa para el público, en tanto que servirá para reabrir heridas que, supuestamente, ya deberían estar cerradas, sino que, además, demuestra que su autor - y, por extensión, Seix Barral — se inclina hacia una preferencia por la ideología anti-Régimen. Dada la imposibilidad de que la obra se publicase con todo su valor literario, o sea, representando de forma verídica la imagen que de España podía tener un exiliado, esta vio la luz en México en 1965 y no se reeditó en nuestro país hasta 1977, a manos de la editorial Zero.

En febrero de 1962 se solicitó la edición de Las mismas palabras $(1963)^{51}$, la segunda novela escrita por Luis Goytisolo. Titulada de forma inicial $L a$ cálida risa, su argumento gira en torno a un grupo de jóvenes cuya intención es fundar una revista. La acción se desarrolla en siete jornadas, y en ellas, más que trabajar para llevar a cabo su objetivo, los personajes

51 Expte. 62-826: La cálida risa, Luis Goytisolo, Madrid, 1962. AGA 03 (50) $21 / 13781$. 
se dedican a salir, tomar copas y hacer excursiones. Con ello, su autor quiso representar la falta de compromiso social por parte de un sector concreto de la sociedad de la época: la juventud burguesa. Sin embargo, esta denuncia no resultó de agrado para el primer censor que leyó el texto, puesto que, aunque autorizó su publicación, indicó que la "libertad de expresión y de lenguaje" atacaba a la moral, por lo que realizó tachaduras en casi ochenta páginas. Esto obligó a Goytisolo y a la editorial a suprimir numerosos pasajes y expresiones, devaluando así su calidad literaria y el mensaje que se quería transmitir. Tras modificar lo indicado, la obra volvió a ser leída por Álvarez Turienzo, que autorizó su publicación, si bien, además de señalar que un número tan elevado de tachaduras debería ser motivo de suspensión total, advirtió que

las tachaduras no han sido tachadas. Han sido simplemente suavizadas, o encubiertos los pasajes. En general, este procedimiento salva la situación, aunque a veces sirve para poner las cosas peor, ya que lo que en la primera lectura era pornografía simplemente, en esta última es pornografía infantilmente camuflada.

El censor no iba muy desencaminado, puesto que, en realidad, se emplearon multitud de sinónimos para camuflar el léxico escogido por Goytisolo inicialmente y se suprimieron los pasajes más conflictivos —aquellos en los que los personajes hablan sobre política, prostitución, relaciones sexuales...- . Un año más tarde, la novela se publicó, y aunque en 1987 fue reeditada por la editorial Alfaguara — contando con la supervisión y la colaboración del propio Goytisolo_- en la actualidad todavía no ha salido a la luz una versión sin tachaduras, en parte por el desinterés del autor, como él mismo ha reconocido en algunas ocasiones ${ }^{52}$.

Otra obra prohibida durante estos ańos es El capirote $^{53}$, de Alfonso Grosso, presentada ante la censura también en febrero de 1962. La novela plantea de forma pormenorizada las vivencias de un jornalero, Juan Rodríguez López, injustamente acusado de robar. Maltratado y encarcelado, su trágico destino culmina con su patética muerte durante una procesión

52 Cristina Suárez, "Luis Goytisolo y la censura franquista en Las mismas palabras", Represura, 3 (2018), en prensa.

53 Expte. 62-952: El capirote, Alfonso Grosso. AGA 03 (50) 21/13793. 
de Semana Santa. "La obra es inadmisible”, afirma el primer lector; "ataca a la moral en sus descripciones, a la Religión en su visión de la Semana Santa y tiene un fondo exacerbado de resentimiento social”, añade para fundamentar la denegación. Ante tal rechazo, Carlos Barral suplicó que se le permitiera a su empresa editar la obra por considerar, entre otros motivos, que no se erige en contra de la moral católica, que no pretende ofender a nadie y que es portadora de una "excepcional calidad estilística" y literaria. Sin embargo, en la revisión posterior, Herrón descarta la buena intención que pudiera residir en Grosso e insiste en que los españoles no deben leer un texto en el que se incide en el resentimiento social del personaje y, por consiguiente, del propio autor. Mientras que en 1964 se publicaron traducciones de El capirote en francés y en ruso, hasta abril de 1966 no salió de las prensas en castellano, gracias a la editorial mexicana Joaquín Mortiz. Otro ejemplo de que la trayectoria literaria de Grosso, en sus inicios, se vio profundamente castigada por la censura lo constituye Con flores a María ${ }^{4}$. En noviembre de 1962, Grosso vio frustrada la publicación de De romería — ese era su título inicial—, un relato sobre los hechos acaecidos durante la festividad de la Virgen del Rocío, en Almonte, entre los que destacan los desagradables pasajes en los que un señorito andaluz queda impune tras haber violado brutalmente a una joven quinceañera. De nuevo, el escenario narrativo resulta familiar al autor e incómodo a los censores, dado que una tradición religiosa típicamente española sirve de pretexto para denunciar los actos de algunos sectores de la sociedad de la época. Es por ello que el primer lector, Dieta, la autoriza con numerosas tachaduras, pero la califica como "aspera" y "dura" tras criticar el sinfín de actos inmorales que reproduce. Especial atención merece la recomendación final del censor:

Esta novela puede ser leída entre nosotros. Fuera de España no. No debería ser traducida ni exportada a América. Refleja mucho la idea que tienen de nosotros. Puede autorizarse con las tachaduras y debería llamarse la atención al INLE [Instituto Nacional del Libro Español] para que se cortase su exportación, si esta se intentase, que no lo creo.

54 Expte. 62-6101: De romería, Alfonso Grosso. AGA 03 (50) 21/14249. 
Consciente de la repercusión internacional que podría suscitar la lectura de la obra en el extranjero, el censor prefiere asegurarse de que eso no ocurra y, por tanto, prohíbe su traducción y exportación. Aún más críticos con el texto fueron los censores religiosos Álvarez Turienzo — "no quedan bien paradas las instituciones políticas ni religiosas" — y Aguirre — "no hay ninguna tesis doctrinal sino tan solo una mera relación de hechos", "abundan escenas eróticas que algunas veces rayan en lo pornográfico", "se queda uno en la duda de si ha pretendido presentar más bien que una imagen de la tradición española, una amarga caricatura de ella”...-. Triplemente rechazada e inédita durante casi veinte años, Con flores a María no se publicó hasta el año 1981.

La lista de novelas imposibles adscritas al Realismo social imperante en la literatura española de los sesenta no acaba con los títulos a los que nos hemos referido, sino que continúa con textos como Fata Morgana, de Gonzalo Suárez, La criba, de Daniel Sueiro, La patria y el pan, de Ramón Nieto, El libro de Caín, de Victoriano Crémer... Queda así expuesto que las dificultades con las que se enfrentaron los autores de la época no fueron pocas, ya que la censura se empeñó al máximo en la lectura y los funcionarios no solo se dedicaron a tachar masivamente, sino que denegaron la autorización de gran parte de estos libros.

\section{Conclusión}

El recorrido trazado deja entrever una posible interpretación del Realismo social como solución ante los callejones sin salida de la censura, objetivados en dos factores fundamentales para entender esta segunda fase de la literatura española bajo el franquismo. Por una parte, fue visto como un lenguaje natural y sencillo que no precisaba de un gran dominio técnico. Así, los autores más jóvenes encontraron un modo de paliar las limitaciones de su formación artística ante el cinturón sanitario que la censura puso respecto a la literatura internacional y a buena parte de la tradición española contemporánea. Por otro lado, la ficción objetiva, en la que el narrador no interviene y los hechos en sí mismos son depositarios de toda la verdad, fue una forma de poner a prueba a la censura y tratar de ser críticos sin ser por ello mutilados. Sin embargo, esta crítica implícita 
terminó por resultar políticamente estéril y estéticamente pobre. Elevar el caudal de crítica en los años sesenta, cuando los censores estaban ya adiestrados en la vigilancia del potencial subversivo de este tipo de escritura, derivó en prohibiciones de publicación y, consecuentemente, en la crisis del paradigma, que puso de manifiesto el espíritu renovador de Tiempo de silencio, de Luis Martín-Santos, en 1962.

Las páginas precedentes demuestran, a partir de un caso particular, cómo cupo a la censura editorial un papel clave como coautora de la historia literaria española del siglo pasado, de sus continuidades y cambios, al forzar a los autores a buscar lenguajes inéditos. Esta dialéctica entre la necesidad de los escritores y sus limitaciones en forma de censura, a fin de cuentas otra forma de autocensura, plantea a los historiadores una posibilidad fértil y todavía poco explorada a la hora de cartografiar nuestra historia contemporánea. 